\title{
Condition Monitoring Method for a Linear-motor-type Rail Brake using an Excitation Inverter
}

\author{
Yasuaki SAKAMOTO Keigo UKITA \\ Electromagnetic Systems Laboratory, Maglev Systems Technology Division \\ Takashi SASAKAWA \\ Maglev Systems Technology Division (Former)
}

\begin{abstract}
Studies have been carried out on a rail brake applying linear induction motor technology. This brake is capable of generating contactless braking force. In addition to the contactless braking, no on-board power supply for energizing this brake is required by using dynamic braking. In order to place this brake into service however a self-diagnosis method for checking the soundness of the device is necessary. Therefore, a condition monitoring method for this brake using an excitation inverter, not using dedicated sensors, was considered and examined on a test bench with a roller rig. Results from these tests clarified that the devised method is useful for self-diagnosis.
\end{abstract}

Key words: rail brake, linear motor, inverter, condition monitoring

\section{Introduction}

An eddy-current-type rail brake in railway vehicles is capable of generating contactless braking force that does not use frictional force (adhesive force) between wheels and rails. The braking force of this brake falls very little in the high velocity range, compared to adhesive brakes, which tend to lose more braking force with increasing velocity. Accordingly, adding this contactless braking force to an adhesive brake, can shorten braking distances and times. In turn, this can help improve safety in emergencies such as sudden natural disasters. However, this type of contactless brake requires a power supply backup in the event of an electric outage. Therefore, as a countermeasure, we have proposed a linear-motor-type rail brake, called a linear rail brake, that applies the principle of dynamic braking of a linear induction motor (LIM), and are conducting research and development on it. The proposed brake has its own supply of electric power required for braking operation from self-generation. So far, we have been studying the application of this brake to trains with a maximum speed of over $130 \mathrm{~km} / \mathrm{h}$. Results so far show that the proposed brake meets functional and performance related requirements [1] [2].

The main components of the linear rail brake are an armature, a mounting mechanism, and an excitation inverter. The functions of each component are as follows. The armature generates braking force, the mounting mechanism pulls the armature up and down under the bogie, and the excitation inverter controls the alternating current and self-power generation in the armature. However, in order to put the proposed rail brakes into service, it is not only necessary to fulfil basic functional and performance related requirements, but to have a self-monitoring method for diagnosing problems such as electrical malfunctions. For the armature, conditions which need monitoring include temperature of the coil, the gap between the brake and the rail, and the traveling direction of the vehicle. Of these conditions, the most important is to ensure that the armature has not unintentionally descended when the brakes are not operating because this must be prevented, for the brake to function soundly. Consequently, monitoring the gap between the rail and the brake is critical.

This paper therefore, discusses use of an excitation inverter, which is on standby when the brake is not operating, for the above-mentioned condition monitoring, without adding a condition monitoring sensor. Assuming use of the proposed brake on an actual vehicle, we devised a condition monitoring method in which calibration is completed during preparatory work on a vehicle while it is immobile. The devised method was installed in the controller of a test inverter to verify its validity on a test bench with a roller rig [1].

\section{Basic configuration of a linear rail brake}

\subsection{Armature and mounting mechanism}

A linear rail brake, as described in Chapter 1, is a type of eddy current rail brake in which the DC electromagnet is replaced with a three-phase AC electromagnet. This AC electromagnet is used as the armature of the LIM facing the rails. An example of the configuration is shown in Fig. 1. The armature is installed in the limited space between the front and rear wheels, and its maximum length is about $1.5 \mathrm{~m}$. On the other hand, the head width of rails used in trunk line sections which is $65 \mathrm{~mm}$, limits the size and shape of LIM, forcing it to be very elongated. In addition, since the secondary side for LIM is an iron ingot rail, the skin effect makes it difficult for magnetic flux and eddy current to enter the inside of the rail cross section from a low slip frequency. For these reasons, LIM linear rail brakes have large leakage reactance, large secondary resistance, and strong non-linearity impedance with respect to the magnitude of the current.

The function of the mounting mechanism keeps the armature pulled up under the bogie frame when the brakes are not operating. On the other hand, when the armature is lowered during braking, the gap between the brake and the rail is kept small and uniform. Therefore, condition monitoring is also required to improve the reliability

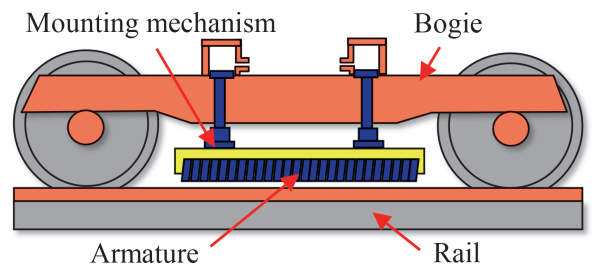

Fig. 1 A configuration example of a linear-motor-type rail brake 
of this mechanism.

\subsection{Excitation inverter}

The basic operation of the excitation system is the power generation braking using the inverter. Here, it is assumed that the supply of power to the inverter and power consumption of the dynamic braking are managed by the main onboard circuit. As such, feeder system failure or regeneration cancellation may affect the excitation system. This means that the excitation system would be unreliable as a braking system. Therefore, we propose a method in which the excitation system is completely independent of the main circuit and an auxiliary circuit powered by a battery is used only for the initial operation of the excitation system. Figure 2 shows an example of how the excitation system could be arranged on a bogie. A diode is inserted between the auxiliary circuit and a capacitor attached to the inverter. When triggered by a brake command, the inverter initially energizes the armature using a small amount of power fed by the auxiliary circuit, and immediately after that, the power generated by the dynamic brake is used to increase the output DC voltage. After reaching a preset DC voltage, the inverter maintains the DC voltage required for its rated operation while maintaining the braking force by controlling the power to balance the power generated and that required for excitation. This excitation method is called the "dynamic braking with zero electrical output." With this excitation method, a simple and highly reliable excitation system can be constructed without using a braking resistor or other similar device.

\section{Monitoring function to be provided}

In addition to the detection of electrical failures (disconnection, short circuit, ground fault, etc.), Table 1 lists the main monitoring functions that the excitation inverter should possess. The elemental technologies required to perform the monitoring functions in Table 1 are summarized in estimations of coil temperature and gap width. Therefore, in this paper, we mainly discuss methods for estimating these. In this discussion, we assume that the preparation process for the monitoring function can be completed in the actual machine while the vehicle is at a standstill in the depot, such as the acquisition of reference data for calibrating the gap estimator.

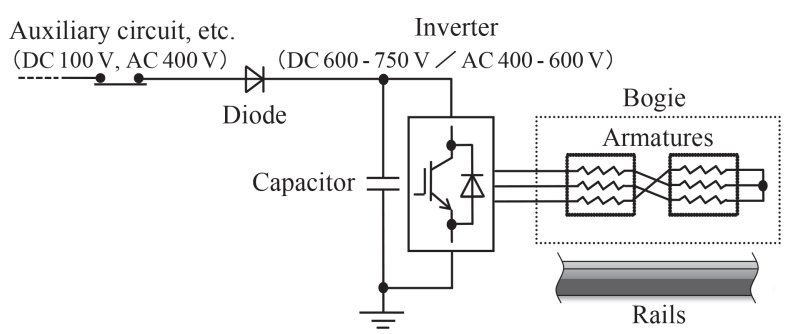

Fig. 2 A basic configuration example of an excitation system
Table 1 Main monitoring functions required for excitation inverter

\begin{tabular}{|l|l|l|l|}
\hline Operating state & $\begin{array}{l}\text { Vehicle } \\
\text { travelling or } \\
\text { standstill }\end{array}$ & $\begin{array}{l}\text { Armature } \\
\text { position }\end{array}$ & Monitoring function to be provided \\
\hline Non-operation & $\begin{array}{l}\text { Travelling or } \\
\text { standstill }\end{array}$ & $\begin{array}{l}\text { Pulled up } \\
\text { (if normal) }\end{array}$ & $\begin{array}{l}\text { i. Coil temperature monitor } \\
\text { ii. Detection of unintended armature descent }\end{array}$ \\
\hline $\begin{array}{l}\text { Gap width } \\
\text { measurement }\end{array}$ & $\begin{array}{l}\text { Travelling or } \\
\text { standstill }\end{array}$ & Lowered & iii. Gap width monitor \\
\hline $\begin{array}{l}\text { Brake operation } \\
\text { started }\end{array}$ & $\begin{array}{l}\text { Travelling } \\
\text { (if normal) }\end{array}$ & $\begin{array}{l}\text { Lowered } \\
\text { (if normal) }\end{array}$ & $\begin{array}{l}\text { iv. Following judgment: } \\
\text { Armature is in lowered position. } \\
\text { Phase sequence is in conformity with } \\
\text { travelling direction. } \\
\text { Vehicle velocity is adequate. }\end{array}$ \\
\hline Brake operation & Travelling & Lowered & $\begin{array}{l}\text { v. Judgment if coil temperature is acceptable } \\
\text { vi. Judgment if gap width is acceptable }\end{array}$ \\
\hline
\end{tabular}

4. Condition estimation / monitoring method focusing on equivalent electrical circuit constants

\subsection{Equivalent electrical circuit of a linear rail brake and its features}

We express the linear rail brake with an equivalent electric circuit like an induction machine such as LIM. Using an equivalent electric circuit, we examine condition monitoring by observing changes in each parameter. Here, the equivalent electrical circuit of the linear rail brake is illustrated in Fig. 3. The meanings of the symbols are $V_{1}$ : primary voltage (input voltage), $I_{1}$ : primary current (input current), $Z_{\text {in }}\left(=r_{\text {in }}+\mathrm{j} x_{\text {in }}\right)$ : input impedance, $Z_{1}$ : primary impedance, $Z_{2 \mathrm{e}}$ : equivalent secondary impedance, $r_{\text {in }}$ : input resistance, $r_{1}$ : primary resistance, $r_{2 \mathrm{e}}$ : equivalent secondary resistance, $x_{\mathrm{in}}\left(=\omega l_{\mathrm{in}}\right)$ : input reactance, $x_{1}$ : primary reactance, $x_{2}$ : equivalent secondary reactance, $l_{\text {in }}$ : input inductance, $l_{1}$ : primary inductance, $l_{2 \mathrm{e}}$ : equivalent secondary inductance and $\omega$ : angular frequency, respectively. This figure is constructed with a concept similar to an equivalent circuit for a general induction machine, but the following points are different.

$x_{1}\left(l_{1}\right)$ : Reactance (inductance) measured with the armature alone without getting close to the rail.

$r_{2 \mathrm{e}}$ : A component of the input resistance $r_{\text {in }}$ measured when

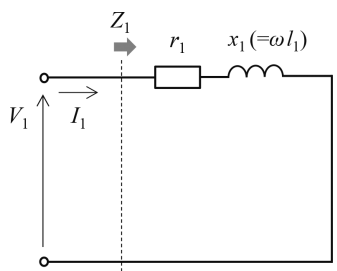

(a) Case of being pulled up (far enough from the rail)

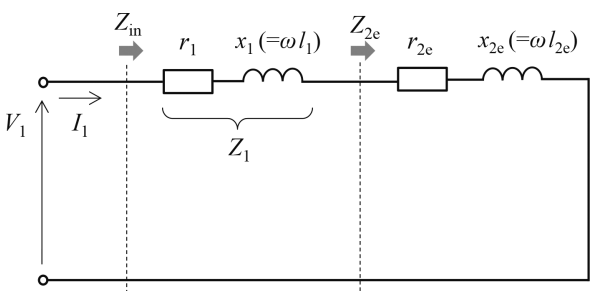

(b) Case of being lowered (close to the rail)

Fig. 3 Equivalent circuits of a linear-motor-type rail brake 
Table 2 Features of equivalent circuit parameters of a linear-motor-type rail brake

\begin{tabular}{|c|c|c|c|c|c|c|c|}
\hline \multirow{2}{*}{$\begin{array}{l}\text { Equivalent circuit } \\
\text { parameters }\end{array}$} & \multicolumn{6}{|c|}{ Dependency of each parameter to the following items } & \multirow{2}{*}{$\begin{array}{c}\text { Conditions for accurate } \\
\text { measurement of each } \\
\text { parameter }\end{array}$} \\
\hline & Coil temperature $T$ & Gap width $g$ & Current $I_{1}$ & Excitation frequency $f_{1}$ & Slip frequency $s f_{1}$ & Vehicle velocity $v$ & \\
\hline $\begin{array}{c}\text { Primary resistance } \\
r_{1}\end{array}$ & $\begin{array}{c}\text { Dependent } \\
\text { (Proportionally when } \\
\text { frequency is low) } \\
\end{array}$ & Irrelevant & Irrelevant & $\begin{array}{c}\text { Dependent } \\
\text { (AC resistance) }\end{array}$ & Irrelevant & Irrelevant & Excitation frequency : low \\
\hline $\begin{array}{c}\text { Primary inductance } \\
l_{1}\end{array}$ & Irrelevant & Irrelevant & Strongly dependent & Almost irrelevant & Irrelevant & Irrelevant & Current : low \\
\hline $\begin{array}{c}\text { Equivalent secondary } \\
\text { resistance } \\
r_{2 \mathrm{e}} \\
\end{array}$ & Irrelevant & Dependent & Weakly dependent & $\begin{array}{l}\text { Dependent }{ }^{*} \\
\text { (Proportionally when } \\
\text { frequency is low) }\end{array}$ & $\begin{array}{c}\text { Dependent* } \\
\text { (Weakly when slip } \\
\text { frequency is high) }\end{array}$ & $\begin{array}{c}\text { Almost irrelevant* } \\
\text { (with longitudinal end } \\
\text { effect) }\end{array}$ & $\begin{array}{l}\text { Excitation frequency : high } \\
\text { Slip frequency : high }\end{array}$ \\
\hline $\begin{array}{c}\text { Equivalent secondary } \\
\text { inductance } \\
l_{2 \mathrm{e}} \\
\end{array}$ & Irrelevant & Dependent & Strongly dependent & Almost irrelevant* & $\begin{array}{l}\text { Dependent }{ }^{*} \\
\text { (Strongly when slip } \\
\text { frequency is high) }\end{array}$ & $\begin{array}{c}\text { Almost irrelevant* } \\
\text { (with longitudinal end } \\
\text { effect) }\end{array}$ & $\begin{array}{c}\text { Current : low } \\
\text { Slip frequency : low }\end{array}$ \\
\hline
\end{tabular}

※ When the mutual changes in excitation frequency, slip frequency, and velocity are conceptually excluded

facing the rail. The resistance added to the primary resistance $r_{1}$ when facing the rail. In a general induction machine, this represents the resistance component of the synthetic circuit of the excitation circuit and the secondary circuit.

$x_{2 \mathrm{e}}\left(l_{2 \mathrm{e}}\right)$ : A component of the input reactance $x_{\text {in }}$ (inductance $l_{\text {in }}$ ) measured when facing the rail. The reactance (inductance) added to the primary reactance $x_{1}$ (inductance $l_{1}$ ) when facing the rail. In a general induction machine, this represents the reactance (inductance) component of the synthetic circuit of the excitation circuit and the secondary circuit.

The characteristics of these equivalent circuit parameters are described in Table 2. From this table, it can be seen that the coil temperature can be estimated only by use of the primary resistor $r_{1}$, and the gap width can be estimated by use of the equivalent secondary resistor $r_{2 \mathrm{e}}$ and the equivalent secondary inductance $l_{2 \mathrm{e}}$. Furthermore, Table 2 shows that appropriate conditions are required for the magnitude of current, the frequency of current, the velocity of vehicle, and the slip frequency in order to estimate the coil temperature and the gap width.

\subsection{Estimation of coil temperature and gap width by energiza- tion for condition monitoring}

It is assumed that energization monitoring is achieved with a small current to reduce power consumption using the exciting inverter when the brake is not in operation. This being the case, the following can be considered as methods for estimating the coil temperature and gap width.

\subsubsection{Overview of estimation method}

\section{(1) Coil temperature}

The coil temperature is estimated using the resistance method using the primary resistance $r_{1}$ observed when the armature is energized at a low frequency while the armature is in the pulled-up position far from the rail.

\section{(2) Gap width}

Method A: The gap width between the brake and the rail is estimated from an approximation expression which shows the correlation between the equivalent secondary resistance $r_{2 \mathrm{e}}$ and gap width obtained in the experiment. Since the equivalent secondary resistance $r_{2 \mathrm{e}}$ is highly frequency-dependent, the frequency must be fixed during the observation. Here, the observation is performed by negative-phase energization at a high frequency so that a high slip frequency can be maintained even if the vehicle velocity changes.

The advantage of this method is that no velocity signal is required. When the armature is in the lowered position, the equivalent secondary resistance $r_{2 \mathrm{e}}$ can be made larger than the primary resistance $r_{1}$ by increasing the frequency. Then the calculation error of the equivalent secondary resistance $r_{2 \mathrm{e}}$ due to the error of the primary resistance $r_{1}$ can be reduced. On the other hand, the disadvantage of this method, is that it is necessary to examine the characteristic of the above-mentioned primary resistance $r_{1}$ with respect to the coil temperature at the frequency used for observation in advance. In addition, it is necessary to estimate the coil temperature and primary resistance $r_{1}$ immediately before estimating the gap width. The influence of "change in slip frequency with respect to the change in vehicle velocity" on the accuracy of gap width estimation is suppressed by the negative phase energization at high frequency, but this influence is the focus point for evaluating the usefulness of this estimation method. In other words, when the armatures are arranged in the same gap width, it is necessary to examine whether the same estimated value can be obtained when the vehicle is stopped and when the speed is maximum.

Method B: The gap width is estimated from an approximation expression which shows the correlation between the equivalent secondary reactance $l_{2 \mathrm{e}}$ and gap width obtained in the experiment. Since the equivalent secondary inductance $l_{2 \mathrm{e}}$ is highly dependent on the slip frequency, a small constant slip frequency close to the synchronous frequency according to the vehicle velocity must be exactly maintained during the observation.

The advantage of this method is that the phase angle of the observed impedance is advantageous in improving the calculation accuracy of the equivalent secondary inductance $l_{2 \mathrm{e}}$. When the slip frequency is small, the reactance component to be observed becomes significantly larger than the resistance component in the input impedance $Z_{\text {in }}$. On the other hand, the drawback is that the excitation frequency must correspond exactly to the vehicle velocity. The degree of velocity-dependent longitudinal end effect, which generally increases as the slip frequency decreases, is the focus point for evaluating the usefulness of this estimation method.

\subsubsection{Implementation procedure}

\section{(1) Measurement of primary impedance}

With the armature in the pulled-up position, a small three-phase current for condition monitoring is applied before the vehicle trav- 
els, and the following components in the primary impedance $Z_{1}$ of the armature are measured.

-Coil temperature estimation: At the coil temperature $T_{0}$ (arbitrary measured value, approximately equal to the ambient temperature at the start of use), the primary resistance $r_{10}$ is measured at a low frequency $f_{1 \mathrm{~T}}$.

-Gap width estimation by method A: At the high frequency $f_{1 \text { gap }}$ used for gap width estimation, the primary resistance $r_{1}$ is measured as a function of the coil temperature $T_{1}$ (measured value).

-Gap width estimation by method B: At any frequency in the range from a low frequency at which the voltage for energizing with a small current exceeds an appropriate PWM modulation factor to the maximum synchronous frequency when the vehicle is traveling, the primary inductance $l_{1}$ is measured.

\section{(2) Coil temperature estimation and armature descent detection}

The primary resistance $r_{1}$ is obtained by energizing at a low frequency $f_{\mathrm{IT}}$ for coil temperature estimation with the armature in the pulled-up position. When the vehicle travels, energization is achieved by positive-phase-sequence. By using the primary resistance $r_{1}$, the estimated value of coil temperature $T_{\mathrm{e}}$ can be obtained by (1).

$$
T_{e}=\left(r_{1} / r_{10}-1\right)\left(234.5+T_{0}\right)+T_{0}
$$

Here, if the armature is unintentionally in the lowered position, the estimated value of the coil temperature will be significantly different from the true value. As a vehicle travels, the input resistance decreases, therefore, the estimated value of coil temperature is lower than the ambient temperature. From this abnormal estimated value of coil temperature, it can be detected that the armature is in the lowered position.

\section{(3) Gap width estimation}

With the armature in the lowered position, the input impedance Zin is observed by energizing a small 3-phase current for condition monitoring.

Method A: The equivalent secondary resistance $r_{2 \mathrm{e}}$ is obtained by using the high frequency $f_{1 \text { gap }}$ for gap width estimation. When the vehicle is traveling, energization is achieved by negative-phase-sequence. The current value in such cases, is the same as in "(1) Measurement of primary impedance" described above. For the calculation of the primary resistor $r_{1}\left(T_{1}\right)$, the estimated temperature $T_{\mathrm{e}}$ immediately before pulling down the armature can be used instead of the measured coil temperature $T_{1}$.

Method B: When the vehicle is at a standstill, the equivalent secondary inductance $l_{2 \mathrm{e}}$ is obtained by using a low frequency in which the voltage for energizing with a small current exceeds an appropriate PWM modulation factor. When the vehicle is traveling, $l_{2 \mathrm{e}}$ is obtained by the frequency near the synchronous frequency, in which the slip frequency must be equal to the low frequency used to measure $l_{2 \mathrm{e}}$ when the vehicle is at a standstill. At this time, the current value is the same as in "(1) Measurement of primary impedance" described above.

Common to methods A and B: During the preparatory process when the vehicle is at a standstill in the depot, the measured gap width is identified by an approximation expression A or B with the equivalent secondary resistance $r_{2 \mathrm{e}}$ or the inductance $l_{2 \mathrm{e}}$ as parameters. In the subsequent estimation, the gap width is calculated from the equivalent secondary resistor $r_{2 \mathrm{e}}$ or the equivalent secondary inductance $l_{2 \mathrm{e}}$ using the approximation expression A or B. Figure 4 shows a schematic representation of the procedure described above.

\subsection{Condition monitoring at the start of brake operation}

At the start of "dynamic braking with zero electrical output" for braking operation, it is necessary to determine whether the generated power meets the common requirement in "Monitoring function to be provided iv" in Table 1 . This can be done by observing the magnitude relationship between the primary resistance $r_{1}$ and the equivalent secondary resistance $r_{2 \mathrm{e}}$. On the other hand, if the generated power cannot be obtained, the question can be easily determined by observing the voltage drop of the smoothing capacitor.

\subsection{Condition monitoring during brake operation}

During "dynamic braking with zero electrical output," the excitation inverter often needs to output the maximum voltage and to energize the armature with as much current as possible. Furthermore, the armature of a linear rail brake has a strong non-linear characteristic of impedance with respect to the magnitude of current. For these reasons, it was found that the method of superimposing the current for condition monitoring in the previous section, on current during braking operation, is not suitable. The estimation methods applicable in this case are described below.

\section{(1) Estimation of maximum coil temperature}

The coil temperature during braking operation is estimated by adding a temperature rise to the estimated coil temperature $T_{\mathrm{e}} \mathrm{ob}-$ tained by monitoring energization immediately before the braking operation. The temperature rise can be calculated using the primary resistance $r_{1}$ at the frequency $f_{1 z}$ of "dynamic braking with zero electrical output," the primary current $I_{1}$, the heat capacity $C_{\text {coil }}$ of the coil, and the energization time $t$. Here, in order to calculate the rise in temperature precisely, it is necessary to understand the precise heat radiating ability. However, heat radiating ability is complicated because it is related to the running wind, the weather, the temperature of the iron core immediately before energization, etc., therefore, it is not easy to understand heat radiating ability precisely. Therefore, it is assumed using a simple calculation model, in which the estimated temperature rise is obtained by multiplying the tempera-

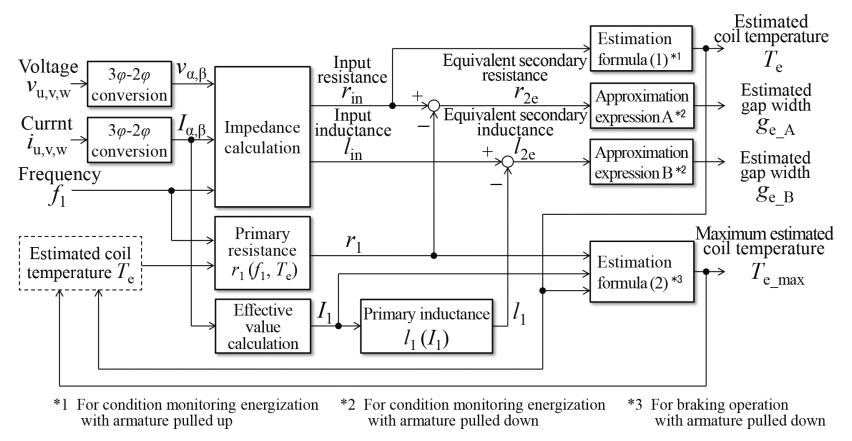

Fig. 4 Basic processing procedure in a condition monitoring 
ture rise value when only the heat capacity of the coil is considered by the correction factor $K$ that simply simulates heat radiation. By adding the estimated temperature rise to $T_{\mathrm{e}}$, the estimated value of maximum coil temperature $T_{\text {e_ } \max }$ is calculated and used for monitoring (2).

$$
T_{\mathrm{e}_{-} \max }=T_{\mathrm{e}}+\frac{K}{C_{\text {coil }}} \int_{0}^{\mathrm{t}} r_{1}\left(f_{\mathrm{lz}}, T_{\mathrm{e}_{-} \max }\right) I_{1}^{2} d t
$$

The initial value of the correction factor $K$ is set to 1 , and then the value is reduced to an appropriate value by comparing it with the test result of the estimated coil temperature $T_{\mathrm{e}}$ obtained by monitoring energization after "dynamic braking with zero electrical output."

\section{(2) Gap width estimation}

In "dynamic braking with zero electrical output," the inverter controls the generated power by adjusting the frequency in order to balance generated power and power consumption. If the inverter outputs the maximum voltage to generate the maximum braking force, the output current changes as the frequency is adjusted. Here, in the velocity range in which "dynamic braking with zero electrical output" can be performed, the power generation capability mainly depends on the gap width. Therefore, during "dynamic braking with zero electrical output," the gap width can be estimated in principle by using the correlation between "change in gap width" and "change in frequency or output current." However, this method requires a vehicle travel test with a gap width measurement by other means and "dynamic braking with zero electrical output" in order to obtain reference data. Since this method cannot be calibrated in the preparatory process when the vehicle is at a standstill, it is not dealt with in this paper.

\section{Verification through bench tests with a roller rig}

In order to verify the condition monitoring method described in the previous chapter, the signal processing shown in Fig. 4 was implemented on the controller of the test inverter to conduct bench tests with a roller rig. For the armature of the linear rail brake, a prototype (Fig. 5) with an arc shape was used for the test bench with a roller rig. This prototype, including the protective cover, has a length of $1,500 \mathrm{~mm}$ or less, a width of $125 \mathrm{~mm}$ or less, and a height of $130 \mathrm{~mm}$ or less when converted to a linear shape. These dimensions are equivalent to an actual machine. As common conditions for the monitoring energization, the voltage was limited to about 5 to $100 \%$ of the rating and the current was limited to about 3 to $10 \%$ of the rating.

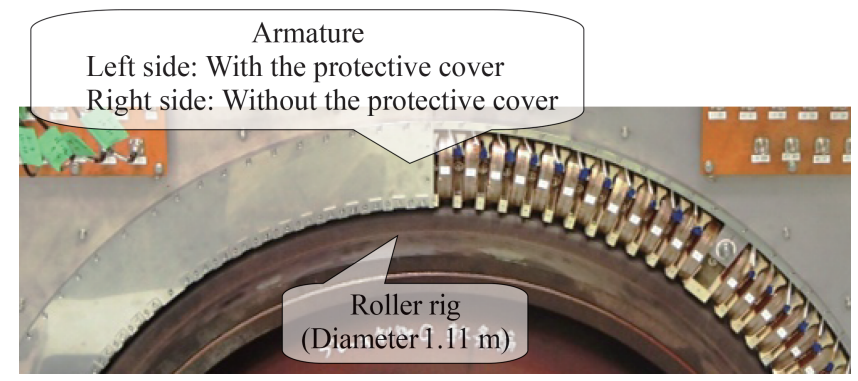

Fig. 5 Exterior of prototype armature for the roller rig test

\subsection{Measurement of primary impedance}

Figure 6 shows the monitored values of the primary resistance obtained by the procedure shown in Fig. 4 with the armature in the pulled-up position. (The monitored values in this figure include the possibility of errors due to discrete-time processing.) The figure shows that the primary resistance tends to increase as the coil temperature increases when the frequency is low. Inversely, when the frequency is high, the primary resistance tends to decrease. Here, the low frequency $f_{1 \mathrm{~T}}$ used for estimating the coil temperature was $10 \mathrm{~Hz}$, and the high frequency $f_{1 \text { gap }}$ used for estimating the gap width by the equivalent secondary resistance was $200 \mathrm{~Hz}$. The primary resistance $r_{1}$ at the frequency $f_{1 \text { gap }}$ can be expressed by the approximate formula (3) (unit: $\mathrm{m} \Omega$ ) with the parameter of coil temperature $T_{1}$

$$
\begin{aligned}
r_{1}\left(T_{1}\right)= & 1.52376 \times 10^{2} \\
& -3.29613 \times 10^{-1} \times T_{1} \\
& +8.44586 \times 10^{-4} \times T_{1}^{2}
\end{aligned}
$$

Figure 7 shows the monitored values of the primary inductance measured using the same method as above. In this figure, the data measured at various frequencies $(10$ to $200 \mathrm{~Hz})$ are displayed together on the same graph. The primary inductance $l_{1}$ can be expressed by the approximate formula (4) (unit: $\mathrm{mH}$ ) with the param-

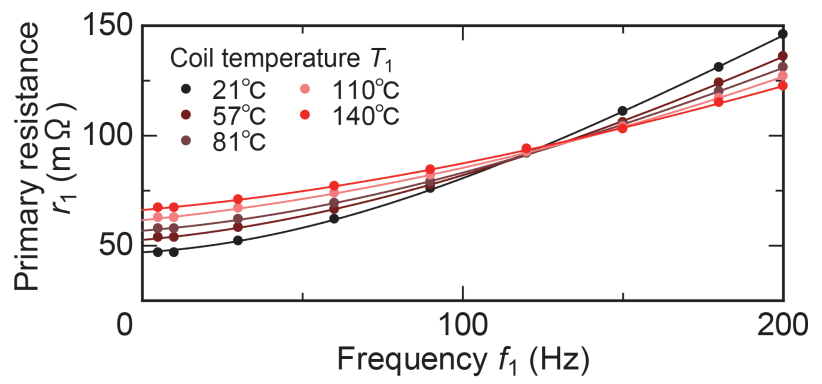

(a) Frequency characteristic

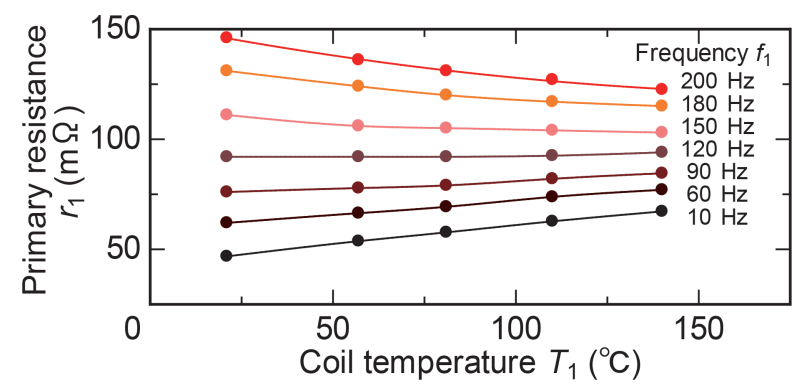

(b) Temperature characteristic

Fig. 6 Monitored values of the primary resistance

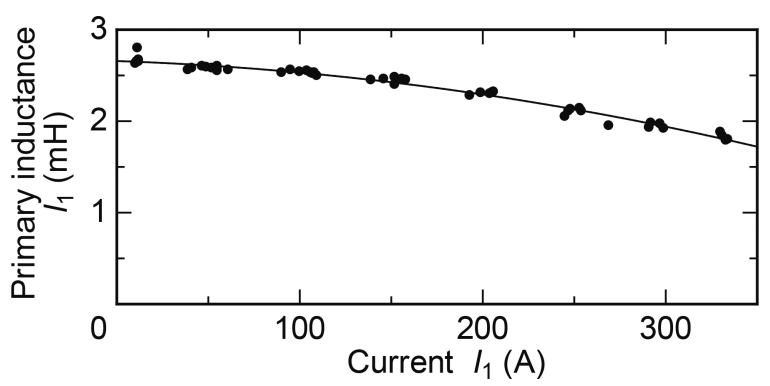

Fig. 7 Monitored values of the primary inductance 
eter of the current $I_{1}$

$$
\begin{aligned}
l_{1}\left(I_{1}\right)= & 2.66836 \\
& -8.14565 \times 10^{-4} \times l_{1} \\
& +5.40178 \times 10^{-6} \times l_{1}{ }^{2}
\end{aligned}
$$

For example, when the current value of the gap width estimation using the equivalent secondary inductance is $10 \mathrm{~A}$, the primary inductance $l_{1}$ is $2.65 \mathrm{mH}$ from (4).

\subsection{Coil temperature estimation and armature descent detec- tion by monitoring energization}

Figure 8 shows the measured values $T_{1}$ and the estimated values $T_{\mathrm{e}}$ by (1) of the coil temperature as a function of primary resistance at $f_{1 \mathrm{~T}}=10 \mathrm{~Hz}$. Here, one set of measured values $\left(r_{1}=46.8 \mathrm{~m} \Omega\right.$, $\left.T_{1}=21^{\circ} \mathrm{C}\right)$ in Fig. 6 was used as reference data $\left(r_{10}, T_{0}\right)$ required for calculating (1). It can be confirmed that the estimated values of the coil temperature correspond with the measured values.

Next, Fig. 9 shows the velocity characteristics when the coil temperature is estimated using the positive phase current of $10 \mathrm{~Hz}$ with a gap width of $6.8 \mathrm{~mm}$ (lowered position). This assumes that the armature unintentionally descended when the coil temperature estimation was being performed at the frequency $f_{1 \mathrm{~T}}=10 \mathrm{~Hz}$. The figure shows that the estimated coil temperature $T_{\mathrm{e}}$ deviates significantly from the true value $\left(\mathrm{T} 1 \cong 30^{\circ} \mathrm{C}\right)$ at all velocities except for about $12.5 \mathrm{~km} / \mathrm{h}$ (synchronous velocity of $f_{1 \mathrm{~T}}=10 \mathrm{~Hz}$ ). The descent of the armature can be detected by using the abnormal indication value of the estimated coil temperature $T_{\mathrm{e}}$. However, this $T_{\mathrm{e}}$ cannot detect the armature descent at the synchronous velocity. By adding to the OR condition that the equivalent secondary inductance $l_{2 \mathrm{e}}$, which is zero at the pulled-up position, exceeds the threshold value, it is possible to detect the armature descent in the entire velocity range.

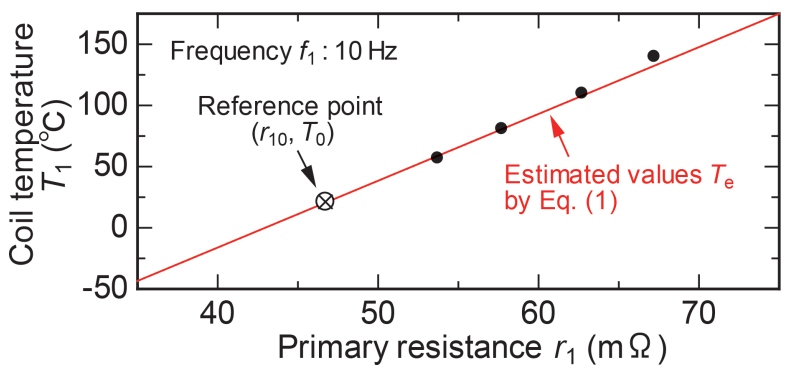

Fig. 8 Comparison of estimated values and measured values in coil temperature

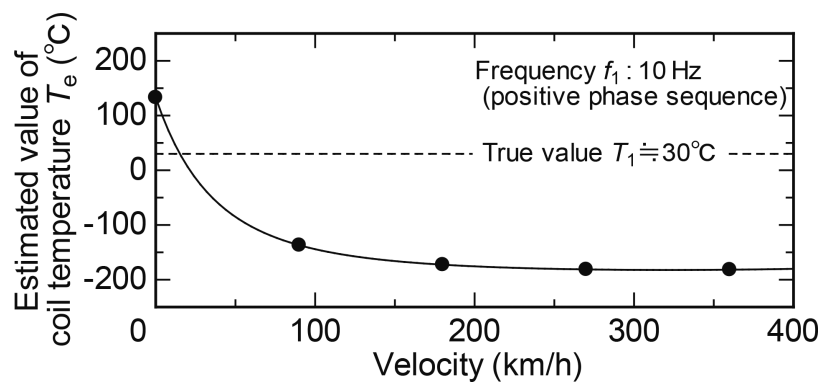

Fig. 9 Abnormal estimated values in coil temperature used to detect armature descent

\subsection{Gap width estimation by monitoring energization}

Figure 10 shows the relationship of the equivalent secondary resistance $r_{2 \mathrm{e}}$ (method $\mathrm{A}$ ) and the equivalent secondary inductance $l_{2 \mathrm{e}}(\operatorname{method} \mathrm{B})$ to the gap width between the armature and roller rig. In this figure, the equivalent secondary resistance and the equivalent secondary inductance have a similar correlation with the gap width. Here, Fig. 11 shows the relationship of the equivalent secondary resistance $r_{2 \mathrm{e}}$ and the equivalent secondary inductance $l_{2 \mathrm{e}}$ to the vehicle velocity. The equivalent secondary resistance $r_{2 \mathrm{e}}$ depends only on the gap width, not on the vehicle velocity. The above-mentioned focus, "change in slip frequency with respect to the change in vehicle velocity," has almost no influence on the equivalent resistance. On the other hand, the equivalent secondary inductance $l_{2 \mathrm{e}}$ tends to decrease slightly with respect to the change in vehicle velocity. This is considered to be the influence of the longitudinal end effect, which is the above-mentioned focus. From these results, method A using the equivalent secondary resistance $r_{2 \mathrm{e}}$ is suitable for gap width estimation, which is less influenced by vehicle velocity.

Figure 12 shows the identification of an approximation expression for gap width estimation by method A using the data in Fig. 10. This approximation expression is identified with the data at a vehicle velocity of $0 \mathrm{~km} / \mathrm{h}$.

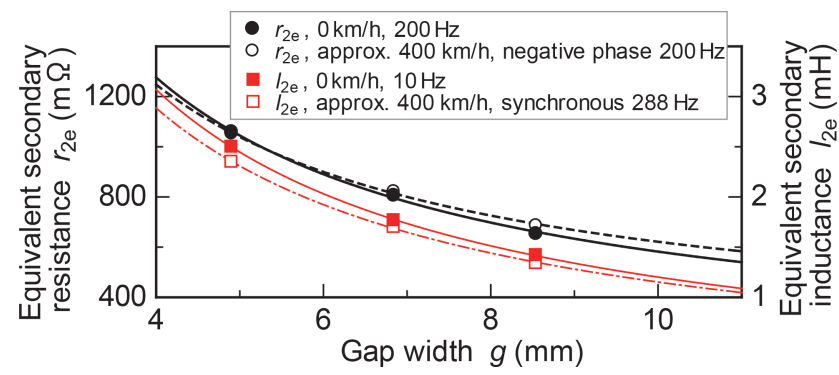

Fig. 10 Equivalent secondary impedance vs. gap width

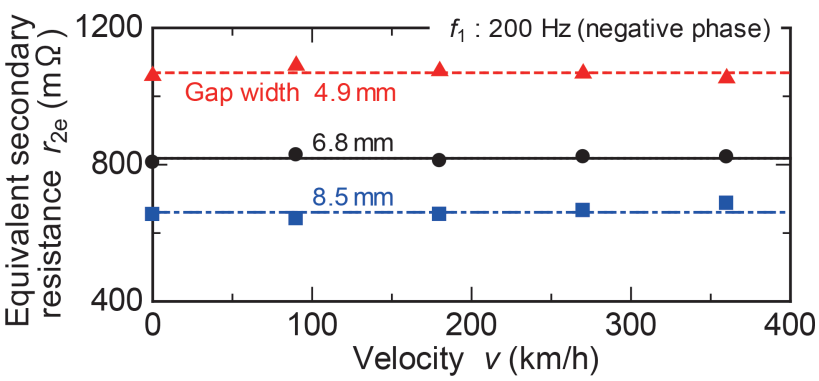

(a) Equivalent secondary resistance for method A

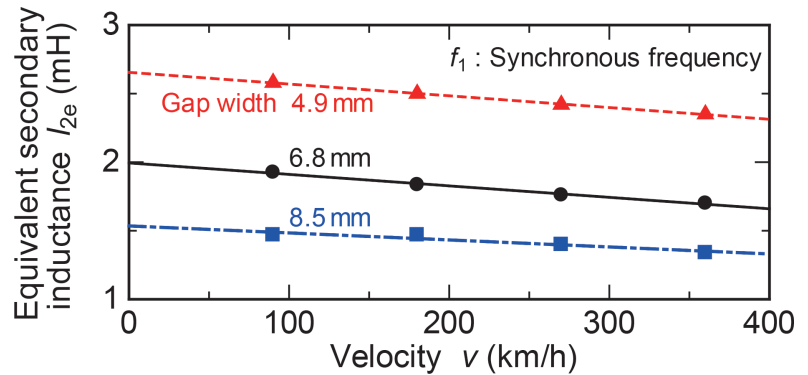

(b) Equivalent secondary inductance for method $\mathrm{B}$

Fig. 11 Characteristics of equivalent secondary impedance vs. velocity 


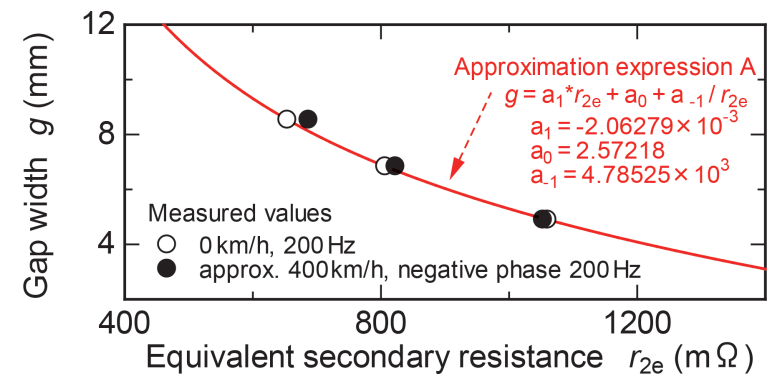

Fig. 12 Example of identification of approximation expression for gap width estimation

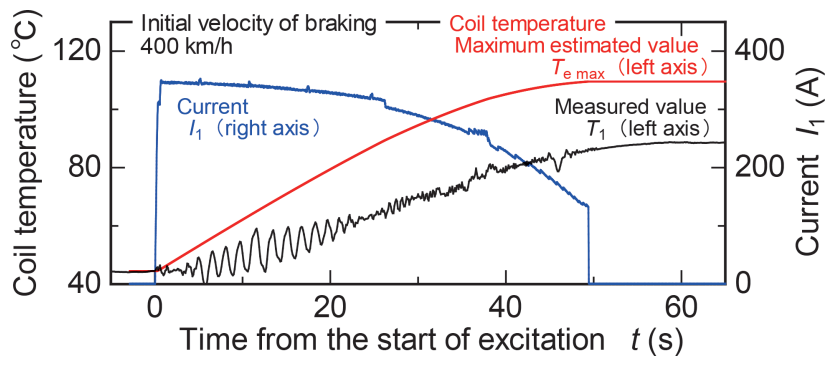

Fig. 13 Maximum coil temperature estimation during brake operation

\subsection{Coil temperature estimation during brake operation}

Figure 13 shows the result of comparing the estimated value $T_{\mathrm{e} \text { max }}$ of the maximum coil temperature obtained by (2) with the measured value $T_{1}$, in the "dynamic braking with zero electrical output" from the initial velocity of $400 \mathrm{~km} / \mathrm{h}$. The correction factor $K$ in (2) is set to 1 . In this test result, the estimated value $T_{\text {e } \max }$ of the maximum coil temperature has a margin of about $40 \%$ with respect to the measured value $T_{1}$. In this case, if the correction factor $K$ is set to 0.68 , the estimated value agrees with the measured value.

\section{Conclusions}

In this paper, we discussed a condition monitoring method using an excitation inverter for the purpose of self-diagnosis of the soundness of a linear rail brake. We implemented the devised method in the controller of the test inverter to conduct the test in a test bench with a roller rig. The following findings were obtained from the results of this test.

- Measuring the primary resistance by monitoring energization using a low frequency $(10 \mathrm{~Hz})$, positive-phase-sequence and small current, makes it possible to estimate the coil temperature using the resistance method and to detect the unintended lowering of the armature.

- Measuring the equivalent secondary resistance by monitoring energization using a high frequency $(200 \mathrm{~Hz})$, negative-phase-sequence and small current, makes it possible to estimate the gap width between the armature and the rail.

- The calibrations of these two methods are the same when a vehicle is running and when a vehicle is at a standstill. Therefore, the calibrations can be completed in the preparation process while the vehicle is at a standstill.

- In the bench tests with a roller rig, the estimated values of the coil temperature rise during braking operation obtained by the simple calculation model agreed with the measured values by setting the correction factor to 0.68 .

\section{References}

[1] Sakamoto, Y., Kashiwagi, T. et al., "Performance of Linear Motor Type Rail Brake Using Roller Rig Test Bench," Quarterly Report of RTRI, Vol. 53, No. 1, pp. 41-45, 2012.

[2] Sakamoto, Y., Kashiwagi, T. et al., "Development of a Rail Brake Derived from Linear Motor Technology," Quarterly Report of RTRI, Vol. 55, No. 2, pp. 105-111, 2014.

\section{Authors}

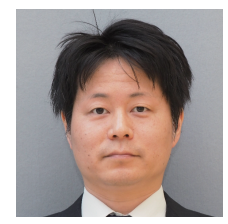

Yasuaki SAKAMOTO, Ph. D.

Senior Researcher, Electromagnetic Systems Laboratory, Maglev Systems Technology Division

Research Areas: Electromagnetic Systems, Linear Motors

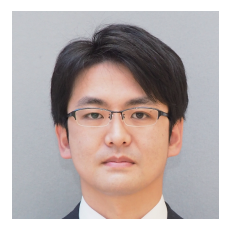

Keigo UKITA

Assistant Senior Researcher, Electromagnetic Systems Laboratory, Maglev Systems

Technology Division

Research Areas: Electromagnetic Systems,

Power Supply Systems

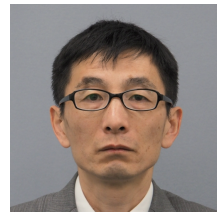

Takashi SASAKAWA, Ph. D.

Senior Chief Researcher, Maglev Systems Technology Division (Former)

Research Areas: Electromagnetic Systems, Magnetic Field Environment 